\section{A Experimentoteca do Centro de Divulgação Científica e Cultural (CDCC-USP): 30 Anos de Contribuições ao Ensino de Ciências}

\author{
Experimentoteca of the Centro de Divulgação Científica \\ e Cultural (CDCC-USP): 30 Years Contributing to Science \\ Teaching
}

\title{
RESUMO
}

Este trabalho trata da Experimentoteca, projeto do Centro de Divulgação Científica e Cultural (CDCC-USP) que busca prover as escolas da educação básica com materiais para a realização de experimentos nas aulas de ciências. Primeiramente, caracterizamos o CDCC enquanto instituição dedicada a difundir a ciência. Depois, narramos a gênese da Experimentoteca apoiados em depoimentos de seus criadores. Finalmente, discutimos os resultados de algumas pesquisas que a tomaram como objeto, considerando os sucessos e os desafios deste projeto, e seu papel enquanto iniciativa de extensão universitária.

Palavras-chave: CDCC. Experimentoteca. Experimentação no Ensino de Ciências. Educação.

\begin{abstract}
This article reports on Experimentoteca, a project undertaken by Centro de Divulgação Científica e Cultural (CDCC-USP) which aims to provide basic education schools with didactic materials so that experiments can be conducted in science classes. Firstly, we characterize CDCC as a science communication institution and then narrate the Experimentoteca's genesis based on testimonials from its creators. Finally, results of some researches into Experimentoteca are discussed, addressing its successes and challenges, as well as its role as an academic extension enterprise.
\end{abstract}

Keywords: CDCC. Experimentoteca. Experimentation in Science Teaching. Education.

Rafael Cava Mori e

Antonio Aprigio da Silva Curvelo

Universidade de São Paulo. Instituto de Química de São Carlos, São Paulo, Brasil 


\section{INTRODUÇÃO}

\section{Em 2014 comemoram-se os 30 anos da Experimentoteca, projeto permanente}

realizado pelo Centro de Divulgação Científica e Cultural (CDCC-USP), unidade da Universidade de São Paulo localizada em São Carlos. A Experimentoteca se apresenta como um laboratório de ciências portátil, disponibilizado para o uso em escolas através de um sistema de empréstimos. É constituída por kits distribuídos em 102 conjuntos temáticos, que correspondem a tópicos dos currículos das disciplinas de ciências físicas e naturais para os ensinos fundamental (64 kits) e médio (38 kits). Os kits são transportáveis por uma única pessoa, e apresentam materiais para o trabalho experimental de até 10 equipes de alunos, muitos de seus itens tendo sido desenvolvidos no próprio CDCC. A utilização da Experimentoteca não envolve qualquer tipo de custo financeiro aos professores ou às escolas. É o próprio CDCC que realiza a manutenção dos kits e a reposição dos materiais consumíveis, graças ao trabalho do setor responsável pela operação do projeto, composto por uma educadora* e seis estudantes de graduação bolsistas.

Neste artigo, seguiremos o seguinte percurso:

Primeiramente, caracterizaremos o CDCC enquanto instituição dedicada a colaborar para a difusão do conhecimento científico e, consequentemente, para a elevação do nível cultural da comunidade de São Carlos e região.

A seguir, falaremos especificamente sobre a gênese e a concepção da Experimentoteca. Nossas principais referências, neste momento, serão depoimentos dos seus próprios criadores, que podem ser considerados como constituintes de uma visão institucional - isto é, da USP, do CDCC - sobre esta iniciativa.

Finalmente, iremos expor o modo como a Experimentoteca se apresenta atualmente, discutindo os resultados de algumas pesquisas que a tomaram como objeto.

Figura 1 - Fachada do CDCC, à rua Nove de Julho, 1227, no centro de São Carlos. Créditos: Rafael C. Mori.

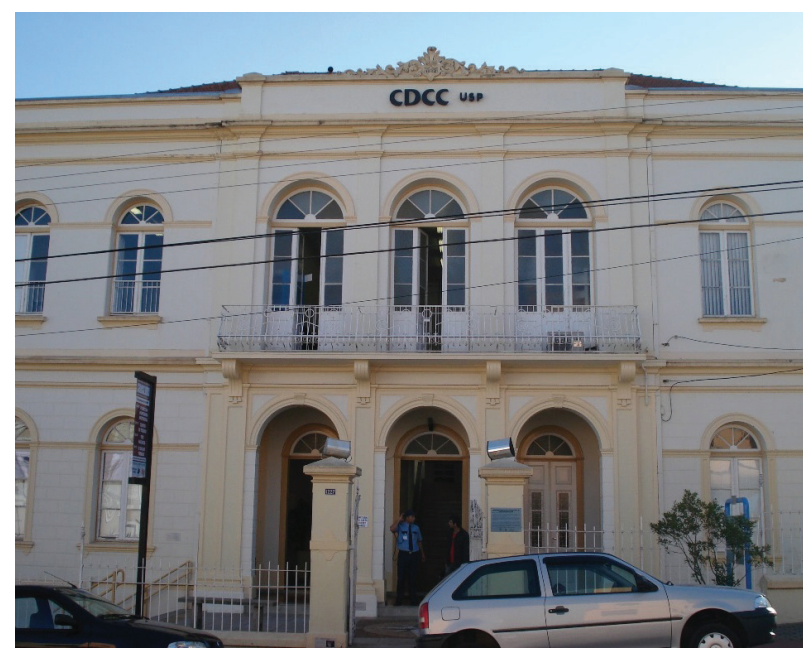

*Vanilde de Fátima Bongiorno, contratada pela USP desde 1985. 


\section{O SURGIMENTO DO CDCC}

O CDCC é um dos diversos centros e museus de ciências criados no Brasil nos anos 1980. Entre instituições que lhe são contemporâneas, podemos citar o Espaço Ciência Viva, no Rio de Janeiro; o Museu de Astronomia e Ciências Afins, também no Rio; a Estação Ciência, em São Paulo; e o Museu Dinâmico de Ciências de Campinas.

Criado em 1980 como uma Coordenadoria de Divulgação Científica e Cultural da USP, surgiu respondendo aos educadores de São Carlos que, reunidos no I Simpósio de Integração Universidade-Escolas de $1^{\circ}$ e $2^{\circ}$ Graus em novembro de 1979, ansiavam por uma maior colaboração entre universidades e profissionais da educação básica para a melhoria do ensino. Especificamente, educadores das disciplinas de ciências físicas e naturais requeriam mais apoio por parte dos docentes universitários das áreas de Física, Química e Biologia - reunidos no então Instituto de Física e Química de São Carlos, da USP, e no Departamento de Ciências Biológicas da Universidade Federal de São Carlos (UFSCar) - para a instrumentação de seu ensino, tanto através do oferecimento de cursos de formação continuada na universidade, quanto pelo desenvolvimento de materiais e roteiros para atividades práticas $[5,9]$.

Inicialmente, a CDCC dispunha de um único funcionário e ocupava apenas uma sala do prédio histórico da Società Dante Alighieri, alugado para as atividades iniciais da USP em São Carlos a partir de 1953. Já estando quase totalmente ocupado pela CDCC desde 1983, em 1985 o prédio foi adquirido pela Universidade (contando com recursos também da CAPES, do CNPq, da Finep e da Secretaria de Educação do Estado de São Paulo) com a finalidade de sediar um centro de ciências [3, 9].

Atualmente, a Coordenadoria, que se tornou Centro em 1995, abrange também um observatório astronômico (no Centro de Divulgação da Astronomia Dietrich Schiel, localizado na área 1 do campus da USP de São Carlos) e mantém diversos espaços para visitação na sede histórica, à Rua 9 de Julho, 1227, bem no centro do município (Figura 1).

Além de exposições de ciências - tanto no ambiente externo de seu prédio, no chamado Jardim da Percepção (Figura 2), quanto no seu interior, onde estão o Espaço Vivo de Biologia e o Espaço de Física - o CDCC realiza uma série de atividades de apoio à educação básica. Na verdade, a atuação deste centro de ciências é, em sua maior parte, voltada para as ações educativas. De fato, no texto de descrição do CDCC presente na coletânea Educação para a ciência: curso de treinamento em centros e museus de ciência [3], ao lado de 12 atividades elencadas como as de maior destaque do centro (excursões e projetos envolvendo educação ambiental; orientação, plantões de dúvidas e minicursos para alunos da educação básica; orientação técnico-científica e cursos para professores da educação básica; palestras e debates sobre astronomia; cineclube; biblioteca e videoteca; atendimentos à distância), apenas um item trata da realização de exposições permanentes e itinerantes.

A exata dimensão da importância das ações educativas do CDCC, entretanto, pode ser apreendida pela análise de seu projeto de maior reconhecimento, impacto e difusão - a Experimentoteca. 
Figura 2 - Mosaico de fotos do Jardim da Percepção, na parte externa do prédio do CDCC. Em sentido horário, a Casa Maluca (percepção da vertical), visitantes utilizando o equipamento da alavanca (percepção da força) e os ambientes de imersão do cerrado e da mata de galeria (percepção do ambiente). Créditos: Rafael C. Mori.
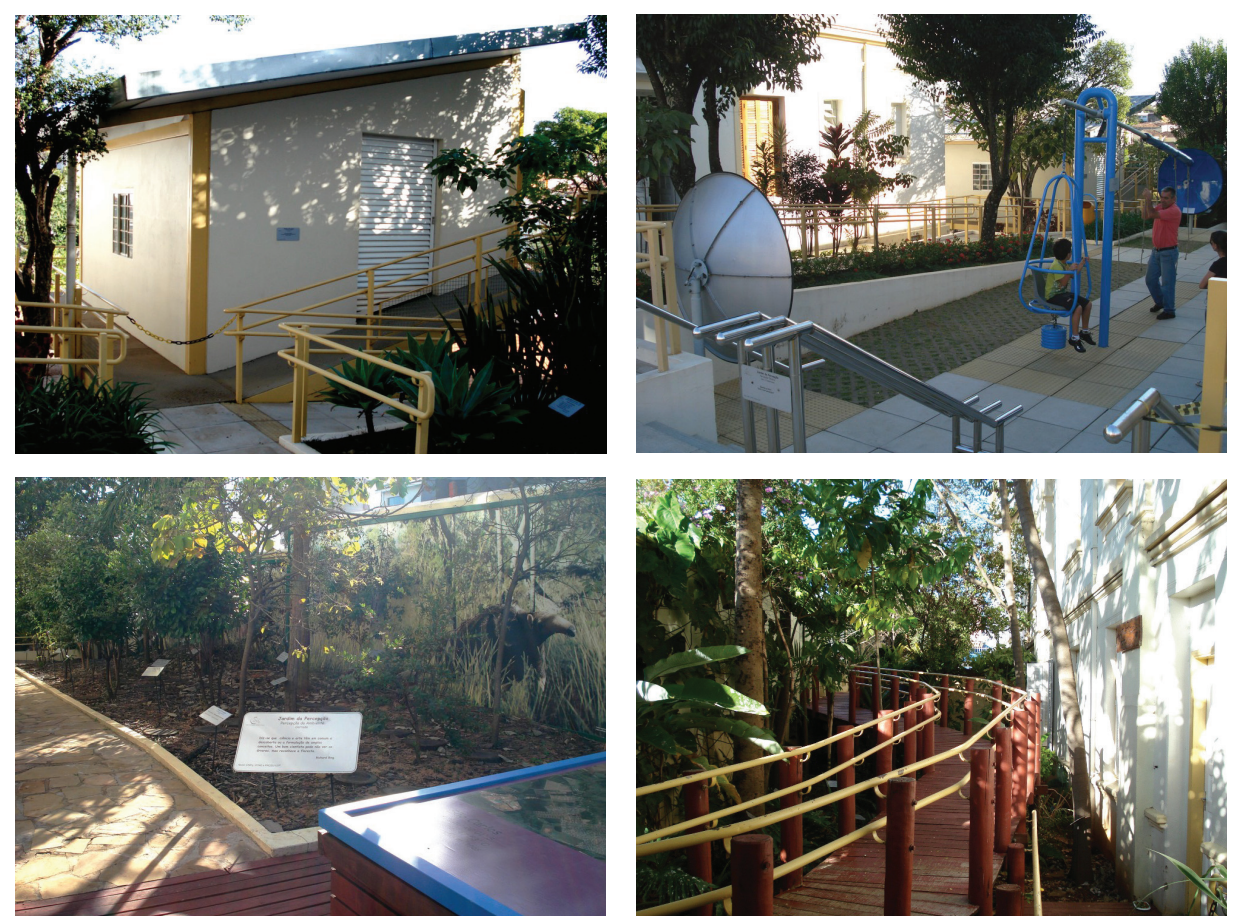

\section{A GÊNESE DA EXPERIMENTOTECA}

Pode-se afirmar que a origem da Experimentoteca remonta a tempos anteriores à própria criação do CDCC.

Enquanto o mundo, polarizado pela Guerra Fria, assistia ao início do embate científico-tecnológico entre União Soviética e Estados Unidos, o Brasil criava, em 1950, o Instituto Brasileiro de Educação, Ciência e Cultura (IBECC). Esta instituição, vinculada à USP e à UNESCO, orientou os diversos setores preocupados com a educação científica brasileira, incluindo os museus, a repensar suas atividades e desenvolver novas iniciativas. Graças ao IBECC, o Brasil se antecipou às grandes potências do ocidente, que só viriam a criar instituições e projetos semelhantes ao final desta década de 1950 [7]. Segundo Gaspar [5], ainda em seus primeiros anos de existência, o IBECC criou o projeto Iniciação às Ciências, produzindo kits de experimentos para alunos da educação básica, contemplando assuntos de física, química e biologia. Os kits continham todo o material para a execução dos experimentos, um manual com orientações e um folheto com leituras suplementares. Uma segunda etapa destas iniciativas pode ser identificada no engajamento do IBECC em traduzir e adaptar os projetos estadunidenses e ingleses de renovação curricular, produzidos na transição da década de 1950 para a de 1960. Estes materiais, orientados de início pela pedagogia tecnicista, propugnavam o método da aprendizagem por redescoberta, através de atividades que pudessem levar à apreensão do método científico, geralmente baseadas na experimentação.

A grande demanda pela produção de material experimental, por parte do IBECC, foi uma das razões que levou à criação da Fundação Brasileira para o Desenvolvimento do 
Ensino de Ciências (FUNBEC) em 1966. Gaspar afirma que, até o final da década de 1960, a parceria IBECC-FUNBEC originaria 15 projetos, alguns envolvendo a produção de kits experimentais, como a Coleção Mirim (30 kits) e a Coleção Cientistas de Amanhã (21 kits).Já na década seguinte, após a promulgação da Lei de Diretrizes e Bases da Educação Nacional n. 5.692/1971, foram produzidas novas coleções de kits, um laboratório portátil de física, biologia e química (projetado para a realização de experimentos em sala de aula) e o projeto Os Cientistas. Esta ação, datada de 1972, compreendeu a elaboração de 50 kits de material experimental vendidos em bancas de jornal, e é considerada por Gaspar a mais importante iniciativa para a divulgação científica já desenvolvida no Brasil. Segundo ele, o primeiro volume da coleção vendeu cerca de 200 mil cópias, e as vendagens se estabilizaram, em volumes futuros, em cerca de 50 mil exemplares.

Impossível não se associar, portanto, a criação da Experimentoteca com a iniciativa pioneira e bem sucedida do IBECC em produzir massivamente materiais para a realização de experimentos didáticos, visando à universalização do método experimental.

Apesar disso, pode-se dizer que o embrião da Experimentoteca nasceu de reivindicações bastante concretas da prática dos educadores de São Carlos, como demonstra o seguinte fragmento das atas do I Simpósio de Integração Universidade-Escolas de $1^{\mathrm{o}}$ e $2^{\circ}$ Graus, reproduzido por Schiel:

Propõe-se a criação de um grupo de trabalho envolvendo físicos, químicos e biólogos para a elaboração de material para os cursos de ciências do primeiro grau [...] Propõe-se que o Instituto de Física e Química de São Carlos ofereça cursos de Instrumentação [... ] cuja finalidade seja a preparação de um conjunto de protótipos e roteiros para os laboratórios nas escolas. Solicita-se que o Instituto de Física e Química de São Carlos estude a viabilidade da construção deste equipamento, devendo o mesmo ficar guardado em um almoxarifado central na cidade, a ser requisitado pelas escolas, quando necessário [9].

Esta "preparação de um conjunto de protótipos e roteiros para os laboratórios nas escolas" teve início, efetivamente, em 1984 [9, 11, 12]. Schiel relata que este ano assistiu ao crescimento das atividades do CDCC como um todo, o que foi motivado pelo surgimento do Programa de Aperfeiçoamento do Desenvolvimento Científico e Tecnológico (PADCT), apoiado pelo Banco Mundial:

Graças à intercedência de Sérgio Mascarenhas, foi possível incluir nesse programa um Subprojeto de Educação para a Ciência (SPEC), base necessária para qualquer desenvolvimento científico e tecnológico. Isso fez com que pela primeira vez surgissem recursos institucionais para projetos auxiliares às Secretarias de Educação que não fossem meros trabalhos de pesquisa educacional, isto é, que aliassem à dimensão da pesquisa uma conotação de extensão universitária, com o propósito explícito de poder influenciar o ensino regular destinado a grandes populações estudantis [9].

Garantidos os recursos financeiros, a gênese da Experimentoteca, para finalmente se consumar, precisou ainda que a equipe do CDCC atacasse três ordens diferentes de problemas ou desafios: a questão operacional, a questão do design e a questão propriamente didático-pedagógica.

A questão operacional diz respeito à própria filosofia orientadora da Experimentoteca. 
Figura 3 - Fotos da Experimentoteca em uma de suas primeiras versões, na década de 1980. Créditos: José Braz Mania.
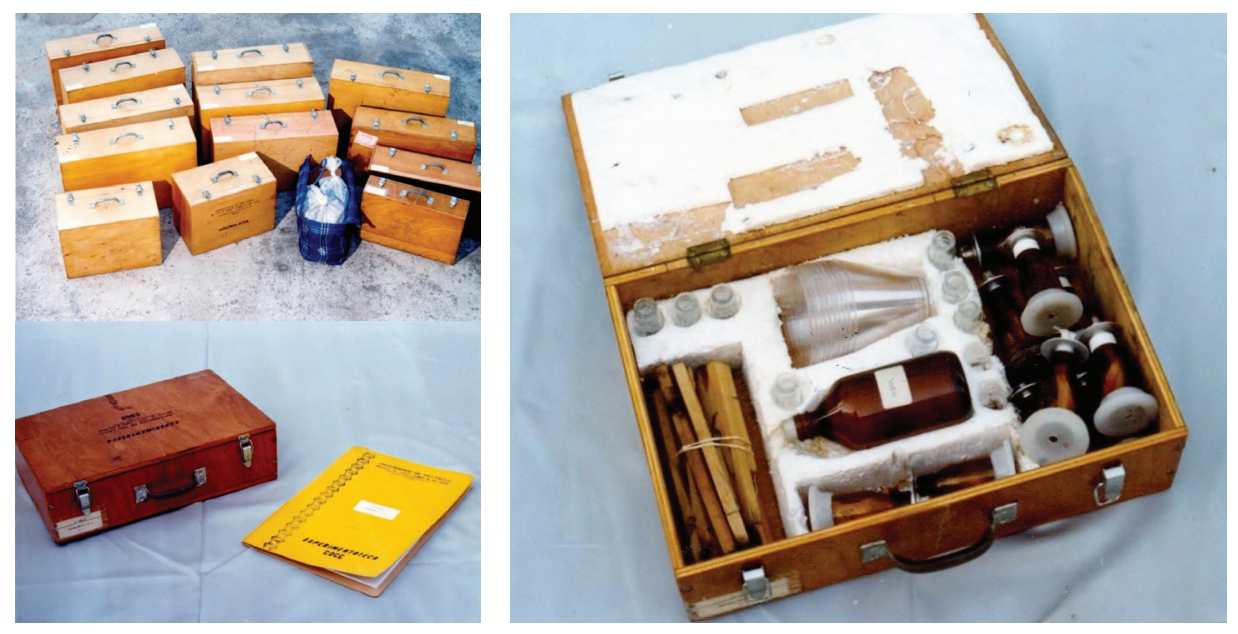

Se a ideia inicial do projeto foi instrumentalizar a prática dos professores de ciências de São Carlos, deveria ser concebida uma forma de se abastecer a educação científica do município com materiais didáticos de fácil acesso e utilização. A maneira encontrada para operacionalizar isto foi a criação do sistema de empréstimo dos materiais desenvolvidos no CDCC por sua equipe interdisciplinar de pesquisadores e técnicos. Assim, o CDCC deveria fornecer estes materiais aos professores da mesma maneira que uma biblioteca é capaz de prover de livros a uma dada população, e vem daí o nome Experimentoteca.

Ao longo dos anos, esta questão operacional foi acrescida de outras saídas práticas que vieram potencializar a viabilidade do projeto em São Carlos. Podemos mencionar, entre estas saídas, a alocação do setor responsável pela Experimentoteca, num primeiro momento, em uma das salas do subsolo do prédio do CDCC, muito próxima à garagem da instituição, facilitando o carregamento de veículos com os kits para seu transporte até as escolas (que é oferecido de forma gratuita às escolas públicas de São Carlos) e, posteriormente, a transferência deste setor para uma casa vizinha ao CDCC, alugada pela USP, permitindo a centralização do trabalho relacionado à Experimentoteca em um único local, sem prejuízos para a mencionada facilidade de acesso aos transportes. Ainda, isto possibilitou melhores condições para a manutenção constante dos kits, exigida pela elevada quantidade de empréstimos.

A questão do design é aquela cuja resolução levou a resultados mais imediatamente apreensíveis pelos usuários da Experimentoteca. A necessidade de produzir um material didático para uso não apenas de professores em demonstrações, mas pelos próprios alunos - em acordo com uma concepção pedagógica crítica ao ensino tradicional - levou a Experimentoteca a se constituir como um conjunto de kits para o trabalho experimental de equipes ou grupos de alunos. Para isso, além de cada kit necessariamente conter material suficiente para o trabalho simultâneo de 10 grupos de quatro estudantes (considerando um máximo de 40 estudantes por sala de aula, nas salas das escolas públicas da educação básica), deveriam ser encontradas maneiras de dispô-lo de modo otimizado em seus "recipientes". As primeiras tentativas de viabilizar a ideia, como relembra Schiel, entrevistado por Luisa Massarani e Fabio Gouveia em novembro de 2002 [10], 
foram marcadas pela modéstia e pelo improviso e, com o passar do tempo, o projeto foi se sofisticando. Assim, no início da década de 1990 o design dos kits foi repensado de modo a se tornar menos amador, a partir de uma parceria com Christian Folz, engenheiro da Faber Castell (indústria que possui sede em São Carlos). No trabalho Projeto Experimentoteca: a contribuição do design [12], os autores relatam as soluções adotadas para a armazenagem dos materiais experimentais em caixas de madeiras facilmente transportáveis por apenas uma pessoa - o que se tornou uma das "marcas registradas" da Experimentoteca -, baseadas em preceitos do campo do design industrial. Entre estes preceitos estão a subordinação da relação forma/conteúdo à qualidade estética, à satisfação do usuário, à possibilidade de produção em série, aos custos e, obviamente, ao perfeito atendimento às finalidades a que o produto se propõe.

Finalmente, há a questão didático-pedagógica propriamente dita, que se impôs mais fortemente nos momentos iniciais da concepção do projeto: desde a própria ideia que motivou a criação da Experimentoteca, discutida pelos professores reunidos no I Simpósio de Integração Universidade-Escolas de $1^{\circ}$ e $2^{\circ}$ Graus, até os primeiros anos de sua existência, em que foram produzidos e testados os primeiros protótipos de materiais. Schiel, falando sobre o modo como a equipe do CDCC se confrontou pela primeira vez com este desafio, argumenta:

A Experimentoteca foi concebida como um meio auxiliar para o ensino de ciências, aliada a leitura, discussões, visitas e a própria aula expositiva. Isso significa que o programa em si não constitui um programa didático mas, como qualquer meio auxiliar, possibilita a criação de maneiras adequadas utilizadas pelo professor [11].

Os idealizadores da Experimentoteca investiram cerca de cinco anos em ciclos de desenvolvimento/aplicação/investigação/novo desenvolvimento dos materiais, até a finalização dos kits para o ensino fundamental. Em fevereiro de 2012, entrevistamos um dos membros da equipe original que planejou a Experimentoteca**, que assim se pronunciou sobre este momento:

Nós fizemos a testagem em escolas, aqui em São Carlos, deste material. Na verdade tem uma pesquisa, em paralelo, no desenvolvimento da Experimentoteca, que é pra ver aspectos didáticos mesmo. Então é assim: não adianta você pensar num kit, pensar num experimento se não sabe como isso vai funcionar em sala de aula, se de fato o aluno aprende, se o professor tem dificuldade, etc. Isso tudo caminhava em paralelo, né, dentro de um projeto grande que é a Experimentoteca.

No entender deste pesquisador, o "projeto Experimentoteca" - ou melhor, o Projeto, com "p" maiúscula - se restringiu apenas a este momento; daí suas declarações de que

** A entrevista fez parte do projeto O laboratório didático e a materialidade do ensino de ciências em São Carlos, que resultou em uma monografia homônima. O trabalho pode ser consultado na Fundação Pró-Memória de São Carlos. 
O Projeto Experimentoteca acabou. Não a Experimentoteca, ela continua, com aportes cada vez mais fortes, mas o Projeto [...] que tinha a equipe inteira trabalhando no desenvolvimento, no teste nas escolas, esse projeto acabou, não existe mais.

Schiel, Curvelo e Ferreira explicam a importância desta fase de testes para a constituição dos kits:

A metodologia do projeto Experimentoteca prioriza ações de intervenção na escola que estejam baseadas na aprendizagem ativa/participativa por meio de atividades cooperativas/interdisciplinares, pois os resultados de pesquisa na área de educação têm mostrado que a simples introdução de inovações tecnológicas, sem a fundamentação teórica/metodológica inerente, é infrutífera e ineficiente. [...] Uma maneira de minimizar esse fator de resistência para a adoção e difusão de propostas inovadoras na educação é envolver os professores na fase de concepção do projeto e, posteriormente, na difusão dos mesmos, dando ao material produzido uma feição articulada com o cotidiano escolar [12].

De qualquer forma, quando o CDCC decidiu expandir a Experimentoteca, de modo a cobrir tópicos do currículo do ensino médio, o Projeto foi retomado. Outra característica interessante do trabalho de concepção e teste dos kits é que a equipe responsável necessariamente teria de envolver profissionais de diversas áreas:

Eu participava, não só na química - eu coordenava toda a parte da química -, mas também nas outras áreas. Isso era legal, que a equipe era bem interdisciplinar. Então é assim, eu trabalhava também os kits de física, de biologia etc., e eu me dedicava muito ao de química, aí eu tinha a equipe própria que trabalhava... [...] o CDCC é muito legal porque, principalmente quando eu tava lá, eu não via muita separação nas atividades por área. Você tem liberdade de atuar de maneira multidisciplinar mesmo. É assim... multi e interdisciplinar. Que é assim, os projetos normalmente eles pegam mais de uma área. Então tem projeto que ele próprio pega física, química, biologia, matemática e tal. É... então ele é multidisciplinar. Mas a equipe trabalha interdisciplinarmente. Você, mesmo sendo químico, você tem participação lá na biologia e entra nisso, desenvolve alguma coisa, e é algo que também ajuda na química e por aí vai.

A Experimentoteca para o ensino médio foi desenvolvida durante dez anos, numa dinâmica que envolveu mais de uma centena de profissionais, entre a equipe do CDCC, professores e alunos da educação básica e colaboradores especialistas em diferentes áreas técnicas.

O conjunto dos depoimentos acima demonstra, portanto, que a Experimentoteca não é apenas um projeto de provimento de materiais didáticos para a educação científica escolar. Por ter envolvido em sua concepção o empenho de profissionais vindos de diversos setores do conhecimento, com destaque para a participação de sujeitos da educação básica como avaliadores dos protótipos, a Experimentoteca se apresenta como uma iniciativa que condensa anos de práxis educacional, materializando as vivências de um grande conjunto de educadores brasileiros dedicados ao ensino das ciências. 


\section{DISCUSSÃO}

\section{Desafios e Perspectivas da Experimentoteca na Atualidade}

Atualmente, a Experimentoteca para o ensino fundamental se encontra disseminada para 31 universidades, centros e museus de ciências em diversos estados do Brasil. Este processo de difusão, ocorrido a partir de 1991, contou com o auxílio da extinta Fundação Vitae. Os recursos desta entidade, que se notabilizou por fomentar projetos envolvendo educação, cultura e promoção social, possibilitaram que a Experimentoteca se tornasse disponível, ainda no início da década de 1990, em mais de 20 cidades, do estado de Santa Catarina ao Pará [10]. A Vitae possibilitou também a publicação, no ano 2000, dos dois volumes d'O livro da Experimentoteca, que reúne os roteiros dos experimentos para o ensino fundamental e apresenta orientações e sugestões aos professores, pedagogicamente fundamentadas em teorias contemporâneas sobre o ensino e a aprendizagem.

Além de sua difusão para outros territórios, é possível afirmar que a Experimentoteca, em termos de sua proposta e seu modelo de funcionamento, alastrou-se para ao menos outro programa desenvolvido no próprio CDCC: trata-se do $A B C d a$ Educação Científica - Mão na Massa. O projeto iniciou-se na década de 1990 com o programa estadunidense Hands On, proposto por Leon Lederman (Prêmio Nobel de Física), estendendo-se à França em 1995 com o apoio de Georges Charpak (outro Prêmio Nobel de Física), onde adotou a denominação La Main à la Pâte. Aportou ao Brasil em 2001 como atividade de cooperação entre as academias de ciências brasileira e francesa, conduzida inicialmente em escala piloto por três centros, a Estação Ciência, a Fundação Oswaldo Cruz e o CDCC.

O Mão na Massa apresenta uma metodologia para o ensino de ciências baseada na investigação, voltada para a educação infantil e às séries iniciais do ensino fundamental. O programa preconiza a realização de atividades diferenciadas em sala de aula, priorizando a discussão, o planejamento, a experimentação e a observação, articulando a aprendizagem do conhecimento científico com o desenvolvimento das expressões oral e escrita. Em São Carlos, as atividades do programa envolvem "cursos de formação continuada [de professores], mostras de trabalhos, produção de material didático e adaptação de material de apoio" [13]. Especificamente quanto a este trabalho de produção de material didático, incorporou-se ao Mão na Massa o desenvolvimento de kits semelhantes àqueles da Experimentoteca, estando hoje disponíveis aos professores, também por um sistema de empréstimo, seis deles. Os temas dos kits são apropriados ao ensino de noções elementares das ciências para os anos iniciais da escolarização: Diagnóstico ambiental, Estados físicos da água, Flutua ou afunda, $O$ céu e a terra, Órgãos dos sentidos e Resíduos sólidos.

Apesar de existir já há três décadas, pouco se produziu a respeito da Experimentote$c a$ em termos de pesquisas acadêmicas. Genuinamente, há apenas três pesquisadores que desenvolveram trabalhos, em nível de pós-graduação, em que ela é tomada como objeto central. Os autores, que produziram dissertações de mestrado na área de Educação - mais especificamente, no Programa de Pós-Graduação em Educação da UFSCar -, são Renato Eugênio da Silva Diniz [2], Célia Lusia Martinelli Joaquim [6] e 
Renata Pereira Canales [1]. Vejamos algumas questões discutidas por estes trabalhos.

Quanto à pedagogia que orientaria os kits, Diniz [2] conclui que seja qual for pois não havia nenhum material do CDCC que a pudesse explicitar, à época em que seu estudo se realizou -, ela seria pouco compatível com uma concepção construtivista, que buscasse relegar grande autonomia aos estudantes. Joaquim [6], em outros termos, afirma algo parecido: a Experimentoteca, pelo próprio caráter dos materiais que a constituem, aproxima-se mais do modelo de laboratório estruturado, ou seja, aquele que promove a experimentação orientada por instruções precisas. Segundo o depoimento de uma professora entrevistada por Canales [1], de fato, as possibilidades de os alunos utilizarem autonomamente o material são remotas, pois geralmente não estão familiarizados com o ensino experimental.

Sendo assim, Diniz [2] acredita ser um ponto negativo da Experimentoteca sua proposta de trabalho com roteiros experimentais bem detalhados, o que tolheria a criatividade dos alunos, tornando sua prática mecânica, automática, irrefletida. Joaquim [6] rebate esta crítica: há a necessidade do roteiro para que as atividades possam ocorrer sem imprevistos que impliquem em desorganização do trabalho escolar. Além disso, não será a existência de um roteiro experimental que conseguirá conter o dinamismo e o espírito criativo e "experimentador" dos jovens, afirma a autora.

Diniz [2] argumenta também que a Experimentoteca pode até ser um facilitador para o trabalho do professor, quanto ao aspecto operacional, não significando, no entanto, que seu uso efetivamente melhore a aprendizagem em ciências. Joaquim [6], em sua defesa do projeto do CDCC, desvia-se um pouco da questão e discorda de seu colega. De modo mais equilibrado, Canales [1] conclui que a Experimentoteca até auxilia na aprendizagem e ajuda a despertar o interesse científico dos alunos, mas em uma intensidade decepcionante. Segundo sua pesquisa, mesmo os alunos expostos aos kits pouco se interessam por carreiras científicas, e não demonstram a aquisição de um vocabulário mínimo para se comunicar em termos do linguajar das ciências.

Apesar de críticas parciais, detectadas no trabalho de Diniz [2], sobre a quantidade de kits e sobre possibilidades de aprimoramento do material, em geral os dados dos três trabalhos respaldam a qualidade da Experimentoteca e sua facilidade de acesso e uso pelos docentes. Não fosse o material do CDCC, muitos estudantes estariam privados de se familiarizar com determinados fenômenos, estudados pela ciência, no próprio ambiente escolar, o que é fundamental para a superação dos conhecimentos do senso comum.

Os trabalhos concordam também que, apesar destas contribuições, a Experimentoteca não é capaz de resolver todas as questões envolvidas na qualidade do ensino de ciências. Existiriam outras mediações, a serem atacadas com a mesma diligência com que o CDCC fez com a questão da experimentação no ensino em São Carlos, cuja resolução deveria ocorrer simultaneamente com o desenvolvimento, a aplicação e a avaliação da Experimentoteca. Estas mediações vão além da iniciativa individual dos docentes e do seu âmbito mais local de ação, e esbarram nas questões implicadas na materialidade da educação - o sistema de ensino, a estrutura organizacional e a continuidade das políticas e iniciativas. 

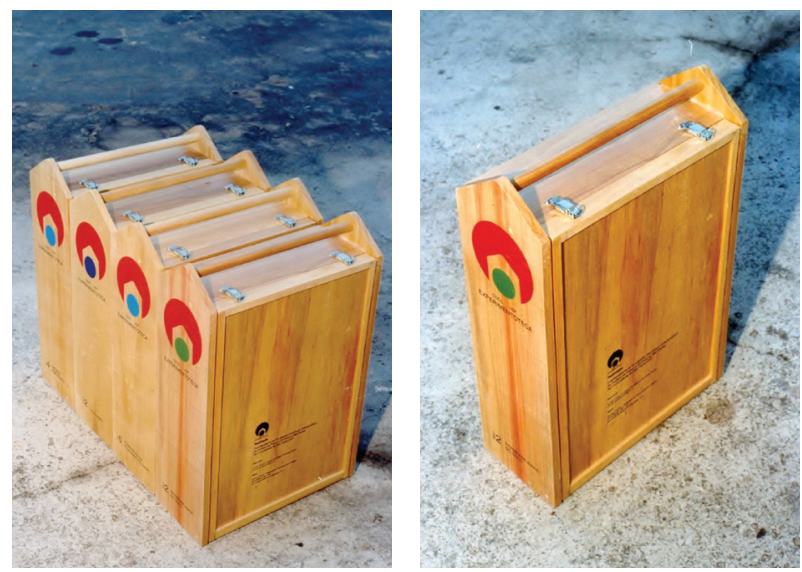

Figura 4 - Mosaico com fotos do interior e do exterior do design atual da Experimentoteca. Créditos: José Braz Mania.
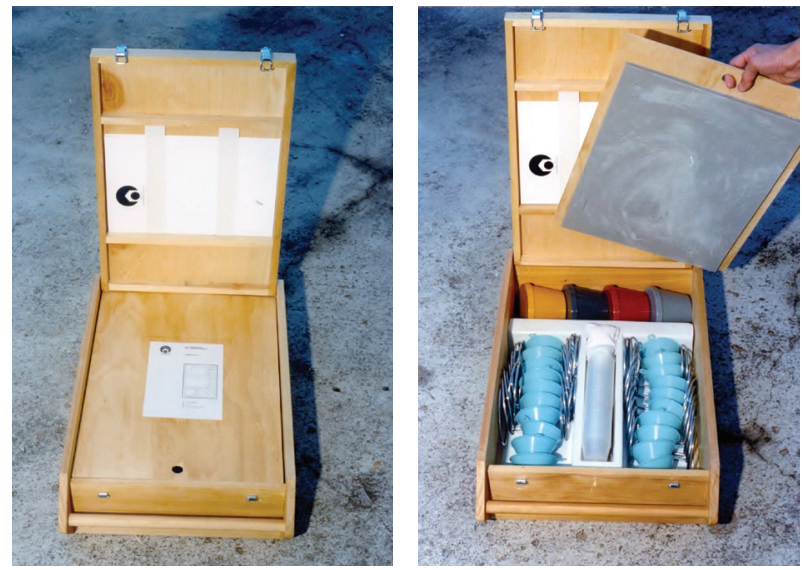

\section{CONCLUSÕES}

A função educativa de órgãos como centros e museus de ciências nunca foi tão valorizada. Entende-se que estas entidades possuem grande responsabilidade, enquanto instituições educacionais, por caberem a elas considerável parte das aprendizagens que não são possíveis durante a (curta) vida escolar dos indivíduos. Atendendo a clamores pela maior participação destas instituições na formação humana, temos visto os centros e museus de ciências se preocuparem cada vez mais com esta sua função educativa: treinam-se mais e melhor os monitores/mediadores, pedagogos passam a se tornar indispensáveis em seu quadro de profissionais, elaboram-se programas de visitas para o recebimento da população escolar, oferecem-se cursos a professores da rede oficial de ensino, e mesmo parte da formação inicial destes docentes passa a ocorrer nestes espaços.

Conforme os depoimentos dos sujeitos envolvidos na concepção e na organização da então Coordenadoria de Divulgação Científica e Cultural - coligidos ao longo deste artigo -, desde seu início esta entidade esteve voltada para a melhoria do ensino de ciências em São Carlos e, posteriormente, em outros municípios. Uma visita ao CDCC confirma que as coleções de objetos, neste centro, são apenas um entre diversos outros elementos, diferentemente do que comumente se reconhece como 
um museu de ciências. Sua vocação é mesmo o fomento ao ensino escolar, em detrimento da ênfase sobre o aspecto expositivo.

Enquanto projeto realizado por uma unidade da USP voltada para a divulgação da ciência e da cultura, a Experimentoteca pode ser enquadrada como um projeto de extensão universitária. Mais do que isso, esta iniciativa do CDCC se mostra em sintonia com uma visão crítica sobre a extensão, que não a reduz a mero assistencialismo, pelo contrário, a concebe como um processo contínuo de elevação do nível cultural da população assistida, que é posta em comunicação (relação recíproca, bidirecional) com o saber científico [4, 8]. Com efeito, a constituição dos kits de materiais didáticos envolveu ampla participação de docentes das escolas públicas de São Carlos e demandou um período prolongado de testes. As sucessivas reformulações pelas quais estes materiais passaram, durante este momento, terminaram por garantir que o produto final materializasse diversos tipos de saber - o saber conceitual das disciplinas científicas, o saber didático-pedagógico, o saber sobre o design - e, portanto, pudesse atender às exigências da práxis educativa neste município e em outras localidades. Portanto, o sucesso da Experimentoteca pode ser atribuído ao fato deste projeto ser o resultado de um abrangente e perene processo de diálogo entre os saberes científicos do mundo acadêmico e os saberes experienciais dos professores da educação básica.

Nem um saber, nem o outro, poderiam sozinhos levar à concretização de um empreendimento como a Experimentoteca, que chega a seus 30 anos como um projeto já consolidado, voltando-se para a melhoria da educação básica brasileira, mas ainda com desafios a enfrentar.

\section{REFERÊNCIAS}

[1] CANALES, Renata Pereira. O Centro de Divulgação Científica e Cultural da Universidade de São Paulo, campus São Carlos: um projeto de extensão universitária. 2006. 143p. Dissertação (Mestrado em Educação) - Centro de Educação e Ciências Humanas, Universidade Federal de São Carlos, São Carlos, 2006.

[2] DINIZ, R. E. S. A experimentação e o ensino de ciências no $1^{\circ}$ grau: analisando a Experimentoteca de $7^{\mathrm{a}}$ série. 1992. 228p. Dissertação (Mestrado em Educação) - Centro de Educação e Ciências Humanas, Universidade Federal de São Carlos, São Carlos, 1992.

[3] FERREIRA, E. R. O.; SCHIEL, D.. Centro de Divulgação Científica e Cultural. In: CRESTANA, S.; HAMBURGER, E. W.; SILVA, D. M.; MASCARENHAS, S. (Orgs.). Educação para a ciência: curso de treinamento em centros e museus de ciência. São Paulo: Livraria da Física, 2001. p. 611-615.

[4] FREIRE, Paulo. Extensão ou comunicação?. Tradução de Rosisca Darcy de Oliveira. Rio de Janeiro: Paz e Terra, 1977. 93 p. (O mundo hoje; v. 24).

[5] GASPAR, A. Museus e centros de ciências: conceituação e proposta de um referencial teórico. 1993. 173p. Tese (Doutorado em Educação) - Faculdade de Educação, Universidade de São Paulo, São Paulo, 1993. 
[6] JOAQUIM, Célia Lusia Martinelli. Estudando a experimentação no ensino de ciências. 1992. 195p. Dissertação (Mestrado em Educação) - Centro de Educação e Ciências Humanas, Universidade Federal de São Carlos, São Carlos, 1992.

[7] KRASILCHIK, Myriam. O professor e o currículo das ciências. São Paulo: EPU, 1987.84p. (Temas básicos de educação e ensino).

[8] SAVIANI, D. Ensino público e algumas falas sobre universidade. 5. ed. São Paulo: Cortez/Autores Associados, 1991. 11op. (Coleção polêmicas do nosso tempo).

[9] SCHIEL, D. Centro de Divulgação Científica e Cultural de São Carlos: o centro de ciência em toda parte. In: CRESTANA, S.; HAMBURGER, E. W.; SILVA, D. M.; MASCARENHAS, S. (Orgs.). Centros e museus de ciência: visões e experiências: subsídios para um programa nacional de popularização da ciência. São Paulo: Saraiva, 1998. p. 189-195.

[10] SCHIEL, D. Colocando a mão na massa. Brasiliana: a divulgação científica no Brasil. Rio de Janeiro, [200-]. Disponível em: <http://www.museudavida.fiocruz.br/ brasiliana/cgi/cgilua.exe/sys/start.htm?infoid=84\&sid=31>. Acesso em: 4 jan. 2014.

[11] SCHIEL, D. A construção do conhecimento pelo aluno no programa Experimentoteca. In: CRESTANA, S.; HAMBURGER, E. W.; SILVA, D. M.; MASCARENHAS, S. (Orgs.). Educação para a ciência: curso de treinamento em centros e museus de ciência. São Paulo: Livraria da Física, 2001. p. 261-264.

[12] SCHIEL, D.; CURVELO, A. A. S.; FERREIRA, L. H. Projeto Experimentoteca: a contribuição do design. Divulgações do Museu de Ciências e Tecnologia (PUCRS), Porto Alegre, v. 4, p. 149-154, 2004.

[13] SCHIEL, D.; XAVIER, A. S. O.; SANTOS, S. A. M.; CASTRO, A. C.; FAGIONATO-RUFFINO, S. Ensino de ciências por investigação. São Carlos: Centro de Divulgação Científica e Cultural/Compacta Gráfica e Editora, 2009. v. 1. 16op.

\section{AGRADECIMENTOS}

Agradecemos à CAPES, pelo financiamento; ao pesquisador entrevistado, pela gentileza em conceder seu depoimento; e aos profissionais do CDCC, em especial ao setor responsável pela Experimentoteca. Este artigo é dedicado à memória do professor Dietrich Schiel (1940-2012), idealizador da Experimentoteca e ex-diretor do CDCC.

RAFAEL CAVA MORI doutorando do Instituto de Química de São Carlos (IQSC-USP) - e-mail: rafael.mori@usp.br

ANTONIO APRIGIO DA SILVA CURVELO professor titular do Instituto de Química de São Carlos (IQSC-USP), diretor do Centro de Divulgação Cientifica e Cultural (CDCC-USP) de 2003 a 2010 e atual membro de seu Conselho Deliberativo. Foi um dos coordenadores do projeto Experimentoteca para o ensino médio - e-mail: aprigio@iqsc.usp.br 